\title{
Solution to gas weighing challenge
}

\author{
Lukas Flierl $^{1} \cdot$ Olaf Rienitz $^{1} \cdot$ Axel Pramann $^{1}$ \\ Published online: 26 June 2020 \\ (C) Springer-Verlag GmbH Germany, part of Springer Nature 2020
}

This Analytical Challenge sets out to develop an equation to obtain mass of gases added to cylinders while accounting for buoyancy corrections [1]. The gas containers have tare masses, e.g., $m_{\mathrm{s}}$, encasing the inner volume $V_{\text {gas }}$. This volume contains an amount of gas, e.g., $m_{\mathrm{A}}$. The total mass of the container and the gas $m_{\mathrm{s}+\mathrm{A}}$ is:

$m_{\mathrm{s}+\mathrm{A}}=m_{\mathrm{s}}+m_{\mathrm{A}}=K_{\mathrm{s}+\mathrm{A}} \times m_{\mathrm{s}+\mathrm{A}}^{\prime}=\frac{1-\frac{\rho_{\text {air }, 1}}{\rho_{\mathrm{cal}}}}{\frac{\rho_{\mathrm{air}, 1}}{\rho_{\mathrm{s}+\mathrm{A}}}} \times m_{\mathrm{s}+\mathrm{A}}^{\prime}$

where $K_{\mathrm{s}+\mathrm{A}}$ is the buoyancy correction factor, $m_{\mathrm{s}+\mathrm{A}}^{\prime}$ is the balance reading, $\rho_{\text {air, } 1}$ is the density of air at the time $t_{1}$ when the mass is recorded, $\rho_{\text {cal }}$ is the density of the calibration mass, and $\rho_{\mathrm{s}+\mathrm{A}}$ is the density of the container filled with gas. The latter can be expressed as follows:

$\rho_{\mathrm{s}+\mathrm{A}}=\frac{m_{\mathrm{s}}+m_{\mathrm{A}}}{V_{\mathrm{s}}+V_{\mathrm{gas}}}$

The numerator is the sum of the mass of the container $m_{\mathrm{s}}$ and the mass of the contained gas $m_{\mathrm{A}}$. This is divided by the sum of the inner volume, $V_{\text {gas }}$, which is the volume occupied by the gas, and the outer volume, $V_{\mathrm{s}}$, which is the volume occupied by the container walls (and valves). If $m_{\mathrm{A}}$ becomes zero (the container is evacuated), Eq. 2 can be rewritten to yield the density $\rho_{\mathrm{s}}$ of the empty container

$\rho_{\mathrm{s}}=\frac{m_{\mathrm{s}}}{V_{\mathrm{s}}+V_{\text {gas }}}$

This article is the solution to the Analytical Challenge to be found at https://doi.org/10.1007/s00216-019-02168-4

Olaf Rienitz

olaf.rienitz@ptb.de

1 Physikalisch-Technische Bundesanstalt, Bundesallee 100, 38116 Braunschweig, Germany
The inverse of $\rho_{\mathrm{s}}$ can be written as:

$\frac{1}{\rho_{\mathrm{s}}}=\frac{V_{\mathrm{s}}+V_{\mathrm{gas}}}{m_{\mathrm{s}}}=\frac{1}{\rho_{\mathrm{m}}}+\frac{V_{\mathrm{gas}}}{m_{\mathrm{s}}}$

Here, $\rho_{\mathrm{m}}$ is the combined density of all metallic parts the container is made from (the walls, the valve etc.). Equation 4 and Equation 1 can be used to find the mass of the evacuated container at time $t_{0}\left(m_{\mathrm{A}}=0\right)$ :

$m_{\mathrm{s}}=\frac{1-\frac{\rho_{\text {air }, 0}}{\rho_{\text {cal }}}}{1-\rho_{\text {air }, 0} \times\left(\frac{1}{\rho_{\mathrm{m}}}+\frac{V_{\mathrm{gas}}}{m_{\mathrm{s}}}\right)} \times m_{\mathrm{s}, 0}^{\prime}$

where $m_{\mathrm{s}, 0}^{\prime}$ is the balance reading of the empty container "s." We assume that the densities of the two evacuated containers are the same within the limits of their uncertainties. We also assume that the ambient conditions (air temperature, humidity, and pressure) do not change significantly during weighing the two containers (for a better understanding of the applied weighing procedure, please see the figure 1 in the challenge [1]). At the time $t_{0}$ (before container "s" is filled with gas), both containers "s" and " $r$ " are evacuated and weighed which provide the following equations:

$m_{\mathrm{s}}=K_{\mathrm{s}, 0} \times m_{\mathrm{s}, 0}^{\prime}$

$m_{\mathrm{r}}=K_{\mathrm{r}, 0} \times m_{\mathrm{r}, 0}^{\prime}$

The masses $m_{\mathrm{s}}$ and $m_{\mathrm{r}}$ are the (tare) masses of the to-be filled container "s" and the empty reference container "r," respectively, whereas $m_{\mathrm{r}, 0}^{\prime}$ and $m_{\mathrm{s}, 0}^{\prime}$ are the balance readings.

After filling the container "s" with gas A and weighing it (at the time $t_{1}$ ), the total mass of the container " $\mathrm{s}$ " is the sum of $m_{\mathrm{s}}$ and $m_{\mathrm{A}}$ :

$m_{\mathrm{s}+\mathrm{A}}=m_{\mathrm{s}}+m_{\mathrm{A}}$

The tare mass $m_{\mathrm{s}}$ at time point $t_{1}$ is

$m_{\mathrm{s}}=K_{\mathrm{s}, 1} \times m_{\mathrm{s}, 1}^{\prime}$ 
Also, container " $\mathrm{r}$ " is weighed at time point $t_{1}$ and its tare mass is

$m_{\mathrm{r}}=K_{\mathrm{r}, 1} \times m_{\mathrm{r}, 1}^{\prime}$

From Eqs. 6 and 9, we can obtain the following:

$m_{\mathrm{s}, 1}^{\prime}=\frac{m_{\mathrm{s}}}{K_{\mathrm{s}, 1}}=\frac{K_{\mathrm{s}, 0}}{K_{\mathrm{s}, 1}} \times m_{\mathrm{s}, 0}^{\prime}$

Since the densities of the two containers are nearly identical, the following relations are valid.

$K_{\mathrm{s}, 0} \approx K_{\mathrm{r}, 0}$ and $K_{\mathrm{s}, 1} \approx K_{\mathrm{r}, 1}$

From Eqs. 11 and 12, it follows that

$\frac{K_{\mathrm{s}, 0}}{K_{\mathrm{s}, 1}} \approx \frac{K_{\mathrm{r}, 0}}{K_{\mathrm{r}, 1}}=\frac{m_{\mathrm{r}, 1}^{\prime}}{m_{\mathrm{r}, 0}^{\prime}}$

Now, Eq. 13 is introduced in Eq. 11 and one obtains

$m_{\mathrm{s}, 1}^{\prime}=\frac{m_{\mathrm{s}}}{K_{\mathrm{s}, 1}}=\frac{m_{\mathrm{r}, 1}^{\prime}}{m_{\mathrm{r}, 0}^{\prime}} \times m_{\mathrm{s}, 0}^{\prime}$

Together, Eqs. 14 and 9 give $m_{\mathrm{s}}$ (following along the lines of Eq. 5):

$m_{\mathrm{s}}=\frac{1-\frac{\rho_{\mathrm{air}, 1}}{\rho_{\mathrm{cal}}}}{1-\rho_{\mathrm{air}, 1} \times\left(\frac{1}{\rho_{\mathrm{m}}}+\frac{V_{\mathrm{gas}}}{m_{\mathrm{s}}}\right)} \times \frac{m_{\mathrm{r}, 1}^{\prime}}{m_{\mathrm{r}, 0}^{\prime}} \times m_{\mathrm{s}, 0}^{\prime}$
Rearranging Eq. 15 leads to

$$
\begin{aligned}
m_{\mathrm{s}}-\rho_{\text {air }, 1} \times\left(\frac{m_{\mathrm{s}}}{\rho_{\mathrm{m}}}+V_{\mathrm{gas}}\right)= & \left(1-\frac{\rho_{\text {air }, 1}}{\rho_{\mathrm{cal}}}\right) \times \frac{m_{\mathrm{r}, 1}^{\prime}}{m_{\mathrm{r}, 0}^{\prime}} \\
& \times m_{\mathrm{s}, 0}^{\prime}
\end{aligned}
$$

The next step is to derive an expression for $m_{\mathrm{s}+\mathrm{A}}$ by combining Eqs. 1 and 2:

$$
m_{\mathrm{s}+\mathrm{A}}=\frac{\left(1-\frac{\rho_{\mathrm{air}, 1}}{\rho_{\mathrm{cal}}}\right)}{1-\rho_{\mathrm{air}, 1} \times\left(\frac{\frac{m_{\mathrm{s}}}{\rho_{m}}+V_{\mathrm{gas}}}{m_{\mathrm{s}}+m_{\mathrm{A}}}\right)} \times m_{\mathrm{s}+\mathrm{A}}^{\prime}
$$

Now, it is important to remember that $m_{\mathrm{s}}+m_{\mathrm{A}}=m_{\mathrm{s}+\mathrm{A}}$ and thus Eq. 17 can be rearranged to

$m_{\mathrm{s}+\mathrm{A}}-\rho_{\mathrm{air}, 1} \times\left(\frac{m_{\mathrm{s}}}{\rho_{\mathrm{m}}}+V_{\mathrm{gas}}\right)=\left(1-\frac{\rho_{\mathrm{air}, 1}}{\rho_{\mathrm{cal}}}\right) \times m_{\mathrm{s}+\mathrm{A}}^{\prime}$

To obtain $m_{\mathrm{A}}$, we need to subtract Eq. 16 from Eq. 18:

$m_{\mathrm{s}+\mathrm{A}}-m_{\mathrm{s}}+\rho_{\mathrm{air}, 1} \times\left(\frac{m_{\mathrm{s}}}{\rho_{\mathrm{m}}}+V_{\mathrm{gas}}\right)-\rho_{\mathrm{air}, 1} \times\left(\frac{m_{\mathrm{s}}}{\rho_{\mathrm{m}}}+V_{\mathrm{gas}}\right)=\left(1-\frac{\rho_{\mathrm{air}, 1}}{\rho_{\mathrm{cal}}}\right) \times m_{\mathrm{s}+\mathrm{A}}^{\prime}\left(1-\frac{\rho_{\mathrm{air}, 1}}{\rho_{\mathrm{cal}}}\right) \times \frac{m_{\mathrm{r}, 1}^{\prime}}{m_{\mathrm{r}, 0}^{\prime}} \times m_{\mathrm{s}, 0}^{\prime}$

This equation can be further simplified which leads to

$$
m_{\mathrm{s}+\mathrm{A}}-m_{\mathrm{s}}=\left(1-\frac{\rho_{\mathrm{air}, 1}}{\rho_{\mathrm{cal}}}\right) \times\left(m_{\mathrm{s}+\mathrm{A}}^{\prime}-\frac{m_{\mathrm{r}, 1}^{\prime}}{m_{\mathrm{r}, 0}^{\prime}} \times m_{\mathrm{s}, 0}^{\prime}\right)
$$

As $m_{\mathrm{s}+\mathrm{A}}=m_{\mathrm{s}}+m_{\mathrm{A}}$, Eq. 20 is the wanted solution for $m_{\mathrm{A}}$ :

$m_{\mathrm{A}}=\left(1-\frac{\rho_{\mathrm{air}, 1}}{\rho_{\mathrm{cal}}}\right) \times\left(m_{\mathrm{s}+\mathrm{A}}^{\prime}-\frac{m_{\mathrm{r}, 1}^{\prime}}{m_{\mathrm{r}, 0}^{\prime}} \times m_{\mathrm{s}, 0}^{\prime}\right)$

If a second gas is added, its mass $\left(m_{\mathrm{B}}\right)$ can be calculated in a similar fashion. At first, an equation just like Eq. 18 must be set up, describing the total mass of container " $\mathrm{s}$ " at the time $t_{2}$. This equation would be

$m_{\mathrm{s}+\mathrm{A}+\mathrm{B}}-\rho_{\text {air }, 2} \times\left(\frac{m_{\mathrm{s}}}{\rho_{\mathrm{m}}}+V_{\mathrm{gas}}\right)=1-\frac{\rho_{\mathrm{air}, 2}}{\rho_{\text {cal }}} \times m_{\mathrm{s}+\mathrm{A}+\mathrm{B}}^{\prime}$

where $\rho_{\text {air, } 2}$ is the density of air at the time $t_{2}$, when container "s" (containing gases A and B) and container " $r$ " are both weighed again $\left(m_{\mathrm{s}+\mathrm{A}+\mathrm{B}}\right.$ is the total mass of container " $\mathrm{s}$ "). The second step is to set up an equation which describes the tare mass of container "s" at the time $t_{2}$; it can be derived like Eq. 18: 
$m_{\mathrm{s}}-\rho_{\text {air }, 2} \times\left(\frac{m_{\mathrm{s}}}{\rho_{\mathrm{m}}}+V_{\mathrm{gas}}\right)=\left(1-\frac{\rho_{\mathrm{air}, 2}}{\rho_{\mathrm{cal}}}\right) \times \frac{m_{\mathrm{r}, 2}^{\prime}}{m_{\mathrm{r}, 0}^{\prime}} \times m_{\mathrm{s}, 0}^{\prime}(23)$

Eq. 23 from Eq. 22, the net gas mass $m_{\mathrm{A}+\mathrm{B}}=m_{\mathrm{A}}+m_{\mathrm{B}}$ can be calculated:

Note that the density of air at $t_{2}$ is different from $\rho_{\text {air, } 1}$ and thus also the balance reading for container "r." By subtracting

$$
\begin{gathered}
m_{\mathrm{s}+\mathrm{A}+\mathrm{B}}-\rho_{\mathrm{air}, 2} \times\left(\frac{m_{\mathrm{s}}}{\rho_{\mathrm{m}}}+V_{\mathrm{gas}}\right)-m_{\mathrm{s}}+\rho_{\mathrm{air}, 2} \times\left(\frac{m_{\mathrm{s}}}{\rho_{\mathrm{m}}}+V_{\mathrm{gas}}\right)=\left(1-\frac{\rho_{\mathrm{air}, 2}}{\rho_{\mathrm{cal}}}\right) \times m_{\mathrm{s}+\mathrm{A}+\mathrm{B}}^{\prime}-\left(1-\frac{\rho_{\mathrm{air}, 2}}{\rho_{\mathrm{cal}}}\right) \times \frac{m_{\mathrm{r}, 2}^{\prime}}{m_{\mathrm{r}, 0}^{\prime}} \times m_{\mathrm{s}, 0}^{\prime}= \\
m_{\mathrm{s}+\mathrm{A}+\mathrm{B}}-m_{\mathrm{s}}=m_{\mathrm{A}}+m_{\mathrm{B}}=\left(1-\frac{\rho_{\mathrm{air}, 2}}{\rho_{\mathrm{cal}}}\right) \times\left(m_{\mathrm{s}+\mathrm{A}+\mathrm{B}}^{\prime}-\frac{m_{\mathrm{r}, 2}^{\prime}}{m_{\mathrm{r}, 0}^{\prime}} \times m_{\mathrm{s}, 0}^{\prime}\right)
\end{gathered}
$$

As Eq. 24 is the total mass of both gases, $m_{\mathrm{A}}$ must be subtracted to obtain $m_{\mathrm{B}}$. This operation (subtracting Eq. 21 from Eq. 24) is summarized in Eq. 26 and the final result is shown in Eq. 26:

$$
\begin{aligned}
& m_{\mathrm{s}+\mathrm{A}+\mathrm{B}}-m_{\mathrm{s}}-\left(m_{\mathrm{s}+\mathrm{A}}-m_{\mathrm{s}}\right)=\left(1-\frac{\rho_{\mathrm{air}, 2}}{\rho_{\mathrm{cal}}}\right) \times\left(m_{\mathrm{s}+\mathrm{A}+\mathrm{B}}^{\prime}-\frac{m_{\mathrm{r}, 2}^{\prime}}{m_{\mathrm{r}, 0}^{\prime}} \times m_{\mathrm{s}, 0}^{\prime}\right)-\left(1-\frac{\rho_{\mathrm{air}, 1}}{\rho_{\mathrm{cal}}}\right) \times\left(m_{\mathrm{s}+\mathrm{A}}^{\prime}-\frac{m_{\mathrm{r}, 1}^{\prime}}{m_{\mathrm{r}, 0}^{\prime}} \times m_{\mathrm{s}, 0}^{\prime}\right) \\
& m_{\mathrm{B}}=\left(1-\frac{\rho_{\mathrm{air}, 2}}{\rho_{\mathrm{cal}}}\right) \times\left(m_{\mathrm{s}+\mathrm{A}+\mathrm{B}}^{\prime}-\frac{m_{\mathrm{r}, 2}^{\prime}}{m_{\mathrm{r}, 0}^{\prime}} \times m_{\mathrm{s}, 0}^{\prime}\right)-\left(1-\frac{\rho_{\mathrm{air}, 1}}{\rho_{\mathrm{cal}}}\right) \times\left(m_{\mathrm{s}+\mathrm{A}}^{\prime}-\frac{m_{\mathrm{r}, 1}^{\prime}}{m_{\mathrm{r}, 0}^{\prime}} \times m_{\mathrm{s}, 0}^{\prime}\right)
\end{aligned}
$$

Inserting the given quantities from the challenge [1] gives the following values:

$m_{\mathrm{A}}=0.9672 \mathrm{~g}$ and $m_{\mathrm{B}}=1.0389 \mathrm{~g}$

Funding information We gratefully acknowledge the support of the Braunschweig International Graduate School of Metrology B-IGSM. The EMPIR initiative is cofounded by the European Union's Horizon 2020 research and innovative program and the EMPIR Participating States.

\section{References}

1. Flierl, L., Rienitz, O., Pramann, A. Gas weighing challenge. Anal Bioanal Chem. 2020;412:1-3. https://doi.org/10.1007/s00216-01902168-4.

Publisher's note Springer Nature remains neutral with regard to jurisdictional claims in published maps and institutional affiliations. 